\title{
A inovação tecnológica à luz dos paradigmas científicos: o lugar das ciências da linguagem
}

\section{The technological innovation through the scientific paradigms: the place of language}

\section{La innovación tecnológica a la luz de los paradigmas científicos: el lugar de las ciencias del lenguaje}

Lêda Pires Corrêa, doutora em Língua Portuguesa pela Pontifícia Universidade Católica de São Paulo. Endereço: Rua das Jangadas, n²0, cj. Beira-Mar I - Bairro Atalaia. CEP: 49037-040 - Aracaju, SE. Telefone: (79) 3243-0318. E-mail: leda-correa@uol.com.br.

\section{Resumo}

O lugar das ciências da linguagem na produção de inovação tecnológica tem sido objeto constante de reflexões e debates entre os especialistas da área no espaço da pós-graduação brasileira. Com o objetivo de possibilitar discussões mais abrangentes e aprofundadas sobre o tema, este artigo apresenta inicialmente uma reflexão sobre o impacto das inovações tecnológicas em diferentes áreas da ciência e da tecnologia, no interior do paradigma moderno, comparadas à revolução técnico-linguística da gramatização. Em um segundo momento, buscase apontar as perspectivas de inovação dos estudos da linguagem no atual contexto brasileiro da pós-graduação, configurado pelos fluxos de transição entre o paradigma moderno, pautado pela razão cartesiana, e o paradigma pós-moderno, que traz à tona o pensamento complexo e multidisciplinar.

Palavras-chave: Inovação Tecnológica. Paradigmas Científicos. Ciências da Linguagem. 


\section{Abstract}

The place of language sciences in the production of technological innovation has been a constant subject of reflection and debate among the specialists of the field within the scenario of graduate education in Brazil. Aiming to enable more comprehensive and thorough discussion on this subject, this study initially presents a reflection about the impact of technological innovation on different areas of science and technology, within the modern paradigm, as compared to the technical-linguistic revolution of grammatization. Secondly, this paper aims to identify the perspectives of innovation in language study in the current Brazilian context of graduate education, as configured by transitional flows between the modern paradigm, guided by the Cartesian reasoning, and the post-modern paradigm, which highlights complex and multidisciplinary thought.

Keywords: Technological Innovation. Scientific Paradigms. Language Sciences.

\section{Resumen}

El lugar de las ciencias del lenguaje en la producción de la innovación tecnológica ha sido objeto constante de reflexiones y debates entre los especialistas de esta área de conocimiento en el ámbito del posgrado en Brasil. Con el objetivo de permitir discusiones más amplias y profundas sobre el tema, este artículo presenta, en primer lugar, una reflexión sobre el impacto de las innovaciones tecnológicas en las diferentes áreas de la ciencia y la tecnología dentro del paradigma moderno, en comparación con la revolución tecno-lingüística de la gramatización. Después, se busca señalar las perspectivas de la innovación en los estudios del lenguaje en el contexto actual del posgrado brasileño que se configura por los flujos de transición entre el paradigma moderno, guiado por la razón cartesiana, y el paradigma posmoderno, que pone de relieve el pensamiento complejo y multidisciplinario.

Palabras clave: Innovación Tecnológica. Paradigmas Científicos. Ciencias del Lenguaje. 


\section{A inovação no paradigma moderno da ciência e tecnologia: o predomínio do modelo da racionalidade}

O telescópio pode ser considerado o evento científicotecnológico inovador de maior relevância para a proposição do modelo de cientificidade baseado na Física e na Matemática que originou o paradigma da ciência moderna. Como postulam Whitehead (1925) e Arendt (1995), o físico, matemático e astrônomo italiano Galileu Galilei instaurou com seu artefato uma concepção astrofísica do mundo, que pôs termo à dicotomia entre o céu e a terra e concretizou a hipótese de Arquimedes, matemático e físico grego, nascido em Siracusa, em 287 a.C., sobre a existência de um ponto de observação fora da Terra, do qual o homem conheceria o mundo sob um prisma universal. Assim, a invenção de Galileu trouxe, por um lado, a certeza do aumento da capacidade dos sentidos do homem por meio da utilização do instrumento telescópio, pelo qual se tornou possível ver e observar a composição estelar da Via Láctea, os satélites de Júpiter, as manchas do Sol e as fases de Vênus e confirmar as especulações de Copérnico sobre a não centralidade da Terra no universo, mas do Sol; e, por outro, gerou a dúvida pela tomada de consciência da limitação sensorial humana.

Depois da invenção do telescópio, aproximaram-se conhecer e fazer. Indiretamente, a descoberta do ponto de vista arquimediano levou à desconfiança em relação a tudo o que é dado e, portanto, “à nova confiança na fabricação e na introspecção, inspirada na esperança de que, na esfera da consciência, o conhecimento e a atividade de produzir coincidiriam" (ARENDT, 1995, p. 309). O método da introspecção, essência da cogitatio cartesiana, único capaz de produzir certezas ou verdades, revelava ao homem a real estrutura da mente, capaz de deduzir e concluir, isto é, de "prever as consequências" dos fenômenos produzidos no interior da consciência, sem a participação do outro, exceto a do produtor do produto. A “fabricação" de formas mentais concebidas como jogo da mente consigo mesma teve na linguagem matemática sua mais perfeita e verdadeira expressão, com a qual se suprimiu a ação dos sentidos, sobretudo a do senso comum - forma coletiva dos sentidos -, pela produção de um sistema de equações matemáticas regido por relações lógicas entre símbolos criados pela mente humana. 
A concepção de conhecimento como processo de fabricação mental provocou a transferência do ponto arquimediano de um espaço cósmico, do qual se explicavam os fenômenos naturais por uma perspectiva universal, para o interior da consciência humana, atribuindoIhe a mesma perspectiva.

A elevação da mente como fabricadora de mundo pela matematização dos fenômenos, por meio do método introspectivo e universalizante, trouxe uma cisão importante na era moderna entre o fazer científico e a produção de instrumentos fabricados pelo homem, que responde por suas tecnologias. Em termos mais concretos, promoveu-se uma cisão entre ciência e tecnologia, por tratar-se de fazeres distintos. Embora ambas gerassem igualmente uma visão mecanicista dos fenômenos da natureza, distinguiam-se pelo modo ou processo de produção.

O conhecimento científico produzido pelo raciocínio cartesiano processa-se pelo fundamento primeiro do "Penso, logo existo" (Cogito ergo sum), segundo o qual toda existência do eu é absolutamente dependente do pensamento, e, como tal, prescreve os imperativos da razão como recursos únicos para a construção da ciência, pois a razão opera por intuições e análises, a exemplo das progressões matemáticas, como afirma Descartes, no final da obra Geometria, "quando se tem os dois ou três primeiros termos, não é difícil encontrar os outros" (DESCARTES, 1954, p. 156). No pensamento cartesiano, o desconhecido e incógnito é necessariamente descoberto a partir do já conhecido, o que revela uma "ordem natural" inerente ao progresso do conhecimento, além de tornar previsivel a narrativa dos fenômenos. Assim, o fazer pelo conhecimento ganha tangibilidade porque obedece aos procedimentos de análise e síntese, que representam a submissão a exigências estritamente racionais. Há, contudo, uma finalidade não utilitária nesse processo de conhecimento, visto que não está no uso a ser feito de seu produto, mas na busca pela verdade fabricada nos domínios estritos da razão, livre da interferência dos sentidos e dos homens. Sua finalidade é a produção de modelos abstratos e ideais.

Caminho oposto segue a produção de instrumentos, cuja relação de meio e fim visa à fabricação de objetos de uso, cujos graus 
de durabilidade e utilidade atestam sua maior ou menor longevidade no conjunto dos artifícios humanos. Contra a subjetividade do homem ergue-se a objetividade do mundo feito por ele. Na medida em que a fabricação se volta para a produção de objetos de uso, o produto acabado tem sua existência e importância graças à durabilidade e é novamente um meio para a produção de outros objetos. Esse círculo vicioso de meios e fins utilitários se transforma na instrumentalização incontida de tudo o que existe. Como tal, cinde-se do conhecimento científico e dele se torna um efeito colateral, um subproduto. Como bem tangível e durável, as tecnologias entram na esfera pública como mercadorias.

A pujança da linguagem dos símbolos matemáticos detentores da fabricação de verdades universais e objetivas e a transformação desse conhecimento em produtos tecnológicos criaram o mundo medido e previsível, no qual se suprimiu o agente do ato do discurso da esfera política.

No plano das ciências sociais, o modelo de racionalidade científica trouxe à luz uma sociologia positivista, cujos procedimentos metodológicos eram transposições das leis da natureza das ciências naturais para as leis da sociedade. No positivismo oitocentista, as ciências sociais nasceram para ser empíricas e configuradas como uma "física social" (SANTOS, 2000).

Teorias do evolucionismo social contribuíram para o fortalecimento das grandes narrativas históricas, cujo enredo impõe "uma imagem ordenada sobre uma mixórdia de acontecimentos humanos" (GIDDENS, 1991, p. 15). E o autor prossegue:

A história "começa” com culturas pequenas, isoladas, de caçadores e coletores, se movimenta através do desenvolvimento de comunidades agrícolas e pastoris e daí para a formação de estados agrários, culminando na emergência de sociedades modernas no Ocidente (Ibidem, p. 15).

Segundo esse autor, a desconstrução desse enredo evolucionista não encontra lugar propriamente nas concepções de ordem e de estabilidade pressupostas no paradigma moderno, mas na observação 
de como a ordem é estabelecida pela relação tempo-espaço nos sistemas sociais. Isso implica considerar que a observância em torno das noções de tempo e espaço possibilita compreender o passado por meio das descontinuidades provocadas pelos diferentes modos de conceber tais noções e não pela concepção da narrativa histórica sequencial e determinante de certa ordem social.

As representações espaciais cartográficas renascentistas, por exemplo, projetam o espaço como um fato da natureza; nesse sentido, passível de ser dominado pelo homem. Por essa razão, “a conquista e organização racional do espaço se tornou parte integrante do projeto modernizador" (HARVEY, 2002, p. 227).

Os mapas renascentistas descrevem com o máximo rigor matemático o espaço terrestre e definem, com crescente grau de precisão, fronteiras territoriais, rotas de comunicação, etc. A utilização dos princípios matemáticos nos mapas iguala, em um mesmo plano, lugares heterogêneos, homogeneizando e reificando, segundo Certeau (2005), a diversidade de itinerários e histórias espaciais.

Não só os mapas, mas também o cronômetro, são tecnologias inovadoras em prol do controle da natureza pela ciência. Segundo Harvey (2002), o cronômetro teve implicações totalizantes no registro do tempo. O conceito de passado e futuro foi associado ao movimento de oscilação linear progressivo e regressivo do pêndulo. Nessa perspectiva, a retrovisão e a previsão eram compreendidas como proposições simétricas, que possibilitavam formular um forte sentido de controle do futuro.

A concepção de mundo-máquina impõe, segundo Santos (2001), a grande hipótese universal da época moderna, o mecanicismo. O modelo de cientificidade cartesiano situa o conhecimento nas operações de quantificação, ordenadamente disposto em um tempo e espaço de controle previsível da natureza e da sociedade, como pré-condição da transformação tecnológica do real, em que as inovações são apanágios do progresso. 
A inovação das ciências da linguagem no paradigma moderno: a gramatização

No domínio das ciências da linguagem, depois do primeiro advento tecnológico da escrita, ocorrido no terceiro milênio antes da era atual, os saberes linguísticos codificados (gramatização) e seus produtos, as gramáticas e os dicionários, encetaram um dos maiores empreendimentos do saber multilíngue e responderam, segundo Auroux (2009), pela segunda revolução técnico-linguística da história, comparável ao advento da astrofísica de Galileu, que the é contemporâneo. As consequências práticas da revolução tecnológica da gramatização, que afetaram profundamente a organização das sociedades humanas, têm precedência sobre as consequências ocorridas pelas ciências naturais - Copérnico, Galileu, Descartes -, como a industrialização, que é um acontecimento mais tardio delas derivado.

Pode-se considerar a gramatização como um macroevento tecnológico de longa duração, que alcança a dimensão da macro-história proposta por Braudel (1990), ao tempo em que se constitui por uma trama complexa de vários acontecimentos no Ocidente, como

a administração dos grandes Estados, a literalização dos idiomas e sua relação com a identidade nacional, a expansão colonial, o proselitismo religioso, as viagens, o comércio, os contatos entre línguas, ou o desenvolvimento dos conhecimentos conexos como a medicina, a anatomia ou a psicologia (AUROUX, 2009, p. 31).

Auroux (2009) afirma que apesar de as ciências naturais terem proposto primeiro o modelo de cientificidade baseado na Física e na Matemática, sua realização e expansão não teriam sido possivveis sem a segunda revolução técnico-linguística da gramatização no Ocidente. Por gramatização entende-se "o processo que conduz a descrevere a instrumentar uma língua na base de duas tecnologias, que são ainda hoje os pilares de nosso saber metalinguístico: a gramática e o dicionário" (AUROUX, 2009, p. 65, grifo do autor).

As gramáticas não são apenas simples descrições da linguagem natural, mas instrumentos linguísticos ou técnicas do conhecimento das 
línguas que prolongam o alcance da fala natural e alteram a geopolítica das línguas. O desenvolvimento massivo da gramatização possibilitou o aparecimento da gramática comparada e da gramática geral de Port Royal no século XVIII pelos enciclopedistas franceses Arnauld e Lancelot. Consagrados linguistas como Arens, Mounin, Robins, Coseriu e Amirova produziram grandes obras sobre a história da linguística; contudo, o fizeram a partir dos critérios institucionalizados do modelo de cientificidade da Física e da Matemática, realizando, pois, a história da linguística, que tem início em meados do século XIX. Auroux (2009), ao considerar o evento tecnológico da gramatização, opta pelo uso da expressão “ciências da linguagem” por ser abrangente e incluir a própria linguística.

Com relação aos dicionários, admite-se, segundo Nunes (2006), a ocorrência do evento da dicionarização, cujo início se deu com a produção intensificada dos primeiros glossários no século VI e dos primeiros dicionários medievais do latim, que foram pouco divulgados e de consulta difícil, dentre os quais se destacam o Papias (século XI) e o Catholicon, de João Balbo de Gênova, impresso por Gutenberg no século XV. Ressaltase que Auroux (2009) não distingue os processos da gramatização e da dicionarização, porque, por muito tempo, pairou uma dificuldade em se distinguir os dicionários propriamente ditos das enciclopédias. Ele cita alguns exemplos, dentre os quais as Etymologias de Isidoro de Sevilha, enciclopédia cujas palavras são sua referência, mas ao mesmo tempo consagra 30 capítulos à gramática, o que dificultou também a distinção entre gramática e dicionário.

De qualquer modo, o saber metalinguístico constituído pela gramatização e pela dicionarização, contemporâneo à concepção astrofísica do mundo científico, não só propiciou a edificação e a difusão das ciências naturais e de suas tecnologias como valorizou a alteridade na dinâmica do processo de descrição das línguas. O paradigma moderno, por conceber como único saber válido e verdadeiro o conhecimento científico, cuja base é a valorização da relação eu↔objeto, desvalorizou a relação eu↔tu (outro) na produção do conhecimento, destituindo o princípio da alteridade pelo divórcio com outras formas de conhecimento. Além disso, a gramatização também forneceu o suporte necessário para 
o florescimento da linguística descritiva no fim do século XIX e início do século XX.

\section{Entre o modelo de racionalidade e o modelo de complexidade: 0 paradigma pós-moderno}

As palavras de Boaventura de Sousa Santos no início da obra Um discurso sobre as ciências resumem metaforicamente a perplexidade instaurada na transição paradigmática do moderno ao pós-moderno:

\footnotetext{
Vivemos num tempo atônito que ao debruçar-se sobre si próprio descobre que seus pés são um cruzamento de sombras, sombras que vêm do passado que ora pensamos já não sermos, ora pensamos não termos ainda deixado de ser, sombras que vêm do futuro, que ora pensamos já sermos, ora pensamos nunca virmos a ser (SANTOS, 2001, p. 5).
}

Para Santos (2001), a transição do modelo de racionalidade ao modelo de complexidade científica apresenta causas teóricas e sociais. No plano teórico, a revolução nas concepções de tempo e espaço decorrente das pesquisas de Einstein relativizou o tempo e espaço absolutos de Newton, pela conclusão de que dois acontecimentos simultâneos em um sistema de referência não são simultâneos em outro sistema de referência. Desse modo, as leis da Física e da Geometria não são universais, como se pensava. Em outros termos, o rigor do conhecimento científico praticado até então perde seu valor de verdade universal e passa a funcionar como probabilidades. Outros dois aspectos resultantes das descobertas de Einstein desencadeiam a quebra no postulado sobre o qual a totalidade do real é igual à soma de suas partes e na dicotomia do conhecimento, que passa a ser concebido no modelo de complexidade, dentro do qual deve predominar a alteridade.

Na esteira das causas sociais do declínio do modelo de racionalidade, Santos (2001) trata da industrialização da ciência, iniciada no começo do século XX, que acarretou o seu comprometimento com os centros de poder econômico e político, os quais assumiram um papel decisivo no delineamento das prioridades científicas. Segundo o autor, 
a aplicação da ciência e a organização científica sofreram a ação desse compromisso. No tocante à aplicação da ciência, cita como exemplo o uso da bomba atômica em Hiroshima e Nagasaki e suas consequências catastróficas à sociedade e à ecologia do meio ambiente. No âmbito da organização do trabalho científico, o autor pondera sobre dois efeitos principais, a saber: a proletarização dos cientistas no interior dos laboratórios e centros de investigação pelo acirramento das relações de poder entre pesquisadores submetidos às demandas científicas determinadas pelos setores econômico e político e o aprofundamento do fosso que se abriu, em termos de desenvolvimento científico e tecnológico, entre os países centrais e periféricos.

A transição atônita entre os dois paradigmas se mostra até no campo das designações moderno e pós-moderno. A prepotência inserida na palavra moderno, que qualifica o longo paradigma que Ihe deu sustentação, exprime "uma atitude profundamente auto (ou ego) cêntrica” (CASTORIADIS, 1992, p. 15), tendendo à anulação de todo desenvolvimento ulterior legítimo. Sob essa designação, podese indagar: o que virá depois do moderno, se ele significa um futuro interminável e, ao mesmo tempo, contradiz as condições de existência da modernidade?

A expressão compósita pós-moderno reflete, por sua vez, o comprometimento com a perenidade do moderno, mas inaugura um novo cenário para a modernidade pela trama do que é complexo. A palavra complexo significa aquilo que é tecido junto e, nesse sentido, todo conhecimento é em si uma prática social, cujo trabalho específico consiste em dar sentido a outras práticas sociais e contribuir para a sua transformação. Segundo Morin (2008), uma sociedade complexa é constituída por várias formas de conhecimento adequadas às práticas sociais. No modelo de complexidade, não há verdades, mas construtos de verdade, via intersubjetividades. A verdade é a retórica da verdade; deve, pois, resultar da negociação de sentidos.

Na transição para o paradigma pós-moderno, observa-se primeiramente a quebra da dicotomização dos conhecimentos. Nesse sentido, o novo paradigma não deve se pautar apenas pelo conhecimento 
científico e tecnológico, mas também pelo conhecimento social, com o qual torna possivel a produção da ciência e tecnologia vinculada às necessidades sociais e humanas com vistas a um desenvolvimento sustentável.

No domínio econômico sob o qual se objetiva o capitalismo globalizado, a sociedade de consumo leva à renúncia da liberdade de agir em favor de um modus vivendi adaptativo. Por essa razão, faz-se necessário restabelecer o equilíbrio entre adaptação e criatividade, de tal modo que as consequências do fazer científico sejam avaliadas antes em termos de custos e benefícios para o homem. Uma prática assim entendida saberá dar à técnica o que é da técnica e à liberdade o que é da liberdade.

Livre das dicotomias modernas, o conhecimento torna-se indiviso, pois resulta das interações e das intertextualidades organizadas em torno de projetos locais. Em outros termos, a ciência pós-moderna deve ser analógica e, como tal,

não virá longe o dia em que a física nos fale do teatro molecular ou a astrofísica do texto celestial, ou ainda a química da biografia das reações químicas. A nudez total, que será sempre a de quem se vê no que vê, resultará das configurações de analogias que soubermos imaginar: afinal, o jogo pressupõe um palco, o palco exercita-se com um texto e o texto é a autobiografia do seu autor. Jogo, palco, texto ou biografia, o mundo é comunicação (SANTOS, 2001, p. 45).

Nesse quadro epistemológico, as ciências da linguagem assumem a capital importância de viabilizar a construção de estratégias textuais e discursivas que respondam pela arquitetura dos saberes e das suas interações.

A inovação das ciências da linguagem no Brasil: perspectivas para a pós-graduação no modelo de cientificidade transicional

Em termos jurídicos e práticos, a inovação liga-se às demandas do mundo econômico e financeiro. No texto da Lei de Inovação $n^{\circ}$ 10.973, de 2 de dezembro de 2004, o conceito inovação se define como 
"introdução de novidade ou aperfeiçoamento no ambiente produtivo ou social que resulte em novos produtos, processos ou serviços" (BRASIL, 2004). Para Spence (2011), a teoria moderna do crescimento defende a hipótese de que o progresso tecnológico (inovação) é parte integrante do modelo econômico, isto é, as bases tecnológicas da economia integram o funcionamento da economia. Há, portanto, um ciclo da inovação representado na Figura 1, que reforça a ligação da produção científica e tecnológica para o fim material do crescimento econômico, por meio do estímulo, via inovação, de um mercado competitivo.

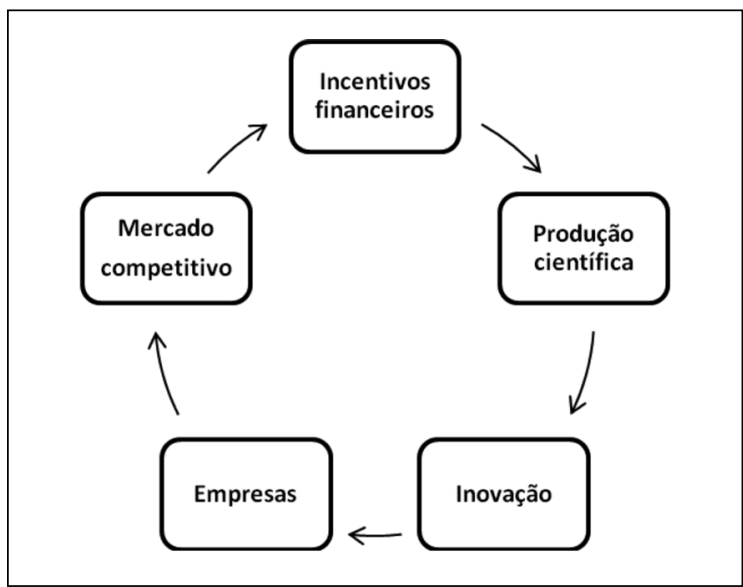

\section{Figura 1. 0 ciclo da inovação, segundo Spence (2001)}

Bourdieu (2004), ao propor a teoria dos campos, defende, por sua vez, a ideia de que um campo só tende a autonomizar-se na medida em que se torna capaz de refratar-se às pressões externas, isto é, de retraduzir para a sua realidade interna as pressões externas. Esse é finalmente o mote para o campo da ciência e da tecnologia no Brasil, sobretudo na área das ciências da linguagem. Como produzir ciência e tecnologia sem margear, por um lado, os limites da ciência pura e quantificadora e, por outro, não submergir na insignificância da ciência escrava?

O campo científico é um mundo social e, como tal, deve realizar percursos relativamente independentes das pressões de outros campos que com ele se relacionam, de tal sorte que as pesquisas não se descontextualizem do momento atual, mas também não estejam totalmente à mercê das determinações de outros campos do saber. 
Esse equilíbrio favorece maior autonomia do campo e abre espaço para uma reflexão necessária entre as instituições e os centros de pesquisas consorciados às políticas econômicas e científico-tecnológicas.

Tal como se deu o evento tecnológico da gramatização, as ciências da linguagem hoje precisam aprofundar os pontos de diálogo entre as pesquisas científicas e tecnológicas da área, no âmbito das pós-graduações stricto sensu, com os órgãos governamentais e, quiçá, com as empresas, sem perderem sua autonomia de decisão sobre que produção é mais relevante no contexto atual.

Não há certamente uma única via para as produções da área na atualidade, mas, em uma breve reflexão, pode-se presumir que a promoção e a difusão da língua portuguesa no mundo despontam como uma grande possibilidade de abertura de divisas para os estudos pós-graduados no Brasil, tendo em vista a posição destacada do País no cenário econômico mundial. Para tanto, as descrições do português brasileiro (PB) representam a contraparte da academia nacional para o delineamento de uma política linguística, na qual a variedade brasileira da língua portuguesa ganha contornos reais em contraste ao português europeu (PE).

O processo de descrição do PB cria condições para a elaboração de tecnologias, como as gramáticas do PB e os dicionários monolíngues de usos dessa variedade. Esses artefatos permitem maior alcance de difusão do português como língua estrangeira (PLE), tendo em vista que a descrição dessa variedade subsidia não só as políticas de promoção do PB como PLE no mundo, mas incentiva também a produção de manuais didáticos e dicionários bilíngues para suprir o alto grau de carência no mercado editorial externo voltado ao ensino-aprendizagem de PLE. Do ponto de vista dos serviços, a difusão do PLE ramifica e diversifica o campo de atuação do profissional de letras.

Embora o cenário mundial venha se revelando bastante favorável à expansão do PB como PLE, o planejamento linguístico não pode se restringir apenas aos gestores públicos, uma vez que é o linguista "que pode indicar o que é tecnicamente possivel fazer e o que será psicologicamente aceitável pelos falantes" (CALVET, 2007, p. 86). 
A Lei $n^{\circ}$ 9394, de 20 de dezembro de 1996, que estabelece as diretrizes e bases da educação nacional, representou um grande avanço nas ações de política e planejamento linguísticos, com sua ênfase nos usos do PB e na valorização da modalidade oral.

No âmbito do Mercosul, questões relativas ao ensino do PB na América Latina ganharam maior destaque por parte das universidades e das associações científicas. Contudo, o Brasil ainda carece da vitalidade de um instituto aos moldes do Instituto Camões. O Instituto Machado de Assis (IMA), embora tenha a missão de promover a língua portuguesa no Brasil e no mundo, em consonância com o Ministério das Relações Exteriores, pouco ou quase nada realiza nessa direção. Segundo Castilho (2010), o governo brasileiro não despertou ainda para essa questão atrelada ao IMA, preferindo gerir os Centros de Cultura Brasileira anexos a várias embaixadas.

\section{Considerações finais}

As reflexões sobre as políticas de inovação aplicadas às políticas sociais, sob o prisma do modelo de cientificidade orientado pela Física e pela Matemática, implicam reassumir a dicotomização dos saberes, que gerou, no passado, uma distância abismal entre o conhecimento científico e o conhecimento do senso comum, além de impedir a construção do objeto de pesquisa pela relação de alteridade e de cindir o fazer científico do fazer tecnológico. Tais dicotomias produziram o progresso das ciências da natureza e de suas tecnologias em uma desproporção considerável em relação às ciências sociais e humanas. Contudo, desde que se leve em conta a revolução técnico-linguística decorrente da gramatização, a edificação e a dominância do paradigma moderno são tributárias desse evento de descrição e instrumentalização linguística e a ele devem sua longa hegemonia.

No período de transição paradigmática, as reflexões sobre as políticas de inovação aplicadas às políticas sociais sofrem uma mudança radical, pois o conhecimento produzido em relação de alteridade impede sua desvinculação da técnica, outrora concebida como mero produto 
do fazer científico. As ações complexas no interior do atual modelo de cientificidade dependem das interações intercampos, sem que isso represente a dominância total de um campo sobre outro. Ocorrem ou devem ocorrer ações concertadas com vários segmentos da sociedade que tenham como principal objetivo o desenvolvimento socioeconômico, cultural e político fundado na sustentabilidade da vida humana no planeta.

No domínio das ciências da linguagem, a intensificação das pesquisas de descrição dos usos do português falado no Brasil subsidiará não só a ampliação do saber metalinguístico, mas levará à tomada de consciência da língua como fenômeno epilinguístico e sua consequente valorização da diversidade de falares do português brasileiro e de sua variedade em relação ao português europeu. Em um movimento dialogado com as instâncias governamentais, os cursos de pós-graduação dessa área do saber podem dinamizar a formação de docentes e pesquisadores capacitados para inovar no espaço intramuros da escola brasileira e na dimensão extramuros das sociedades transnacionais pela promoção e difusão do português como língua estrangeira.

Recebido 30/04/2012

Aprovado 26/10/2012

\section{Referências bibliográficas}

ARENDT, H. A condição humana. Rio de Janeiro: Forense Universitária, 1995.

AUROUX, S. A revolução tecnológica da gramatização. Campinas, SP: Editora da Unicamp, 2009.

BOURDIEU, P. Os usos sociais da ciência: por uma sociologia clínica do campo científico. Tradução por Denice Barbara Catani. São Paulo: Unesp, 2004.

BRASIL. Lei n ${ }^{\circ} \mathbf{1 0 . 9 7 3}$, de 2 de dezembro de 2004. Dispõe sobre incentivos à inovação e à pesquisa científica e tecnológica e dá outras providências. 
Disponível em: <http://www.planalto.gov.br/ccivil_03/_Ato20042006/2004/Lei/L10.973.htm>. Acesso em: 22 abr. 2012.

BRAUDEL, F. História e ciências sociais. Lisboa: Presença, 1990.

CALVET, L-J. As políticas lingüísticas. Tradução por Isabel de Oliveira Duarte, Jonas Tenfen, Marcos Bagno. São Paulo: Parábola: Ipol, 2007.

CASTILHO, A. T. de. Nova gramática do português brasileiro. São Paulo: Contexto, 2010.

CASTORIADIS, C. As encruzilhadas do labirinto, Ill: o mundo fragmentado. Tradução por Rosa Maria Boaventura. Rio de Janeiro: Paz e Terra, 1992.

CERTEAU, M. de. A invenção do cotidiano: artes de fazer. Rio de Janeiro: Vozes, 2005.

DESCARTES, R. The geometry of Rene Descartes. New York: Dover Science, 1954.

GIDDENS, A. As consequências da modernidade. Tradução por Raul Fiker. São Paulo: Editora Unesp, 1991.

HARVEY, D. Condição pós-moderna. Tradução por Adail Ubirajara Sobral e Maria Stela Gonçalves. São Paulo: Loyola, 2002.

MORIN, E. A cabeça bem-feita: repensar a reforma, repensar o pensamento. Rio de Janeiro: Bertrand, 2008.

NUNES, J. H. Dicionários no Brasil: análise e história do século XVI ao XIX. Campinas, SP: Pontes, 2006.

SANTOS, B. de S. A crítica da razão indolente: contra o desperdício da experiência. São Paulo: Cortez, 2000.

Um discurso sobre as ciências. Porto: Afrontamento, 2001. 
SPENCE, M. Os desafios do futuro da economia: o crescimento econômico mundial nos países emergentes e desenvolvidos. Tradução por Leonardo Abramowicz. Rio de Janeiro: Elsevier, 2011.

WHITEHEAD, A. N. Science and the modern world: lowell lectures. London: London Scientific Book Club, 1925. 